\title{
MOVIMENTOS SOCIOAMBIENTAIS E GESTÃO DOS RECURSOS NATURAIS NO CENÁRIO AMAZÔNICO: AÇÕES DA CONFEDERAÇÃO DOS POVOS INDÍGENAS DA BOLÍVIA
}

\section{Social environmental movements and management natural resources in the Amazon scenario: Action of indigenous confederation in Bolivia}

Luciana Aparecida Iotti Ziglio

Doutora em Ciências Humanas pela Universidade de São Paulo lziglio@usp.br

Maria Angela Comegna Mestre em Geografia Humana pela Universidade de São Paulo macomegna@uol.com.br

Artigo recebido em 20/01/2013 e aceito para publicação em 18/03/2013

RESUMO: Fornecer elementos para a análise da formação e da atuação de movimentos socioambientais e repensar as formas de gestão dos recursos naturais e os conflitos decorrentes que estão em andamento são justificativas para esse estudo. Pretende-se, assim, oferecer elementos que possam tanto contribuir com estudos de modelos de gestão de recursos naturais quanto subsidiar políticas de promoção do desenvolvimento sustentável regional. Dessa maneira, à luz dos conceitos “desenvolvimento sustentável” e "racionalidade ambiental”, verificou-se a atuação do movimento socioambiental Confederación de Pueblos Indígenas de Bolivia - CIDOB, e sua influência sobre práticas sociais relacionadas à conservação e sustentabilidade dos recursos naturais. Para tanto, utilizou-se como metodologia de trabalho análise de bibliografia sobre o tema e documentos produzidos pela CIDOB, muitos deles acessados eletronicamente.

Palavras-chave: CIDOB, Bolívia, Amazônia, movimentos socioambientais, gestão dos recursos naturais.

ABSTRACT: Provide inputs for the analysis of training and performance of environmental movements and rethink the ways of managing natural resources and conflicts arising that are in progress are justifications for this study. The aim is thus to offer both elements that can contribute to studies of models of natural resource management, as support future policies to promote sustainable regional development. Thus, in light of the concepts of sustainable development and environmental rationality, we tried to verify the performance of the Confederation of Indigenous People of Bolivia - CIDOB face to environmental issues and their influence on social practices related to the conservation and sustainability of natural resources. Therefore, it was used as working methodology analysis of literature on the topic and documents produced by CIDOB, many of them accessed electronically.

Key words: CIDOB, Bolivia, Amazon, environmental social movements, environmental management. 


\section{INTRODUÇÃO}

A humanidade ao longo de sua existência relaciona-se com o meio ambiente e nele encontra os mecanismos para sua reprodução. Desde a Pré- História, o homem por meio dos animais obtém alimento e vestimentas, dos recursos naturais como madeira, rochas, água, constrói sua moradia, por meio da energia solar consegue obter alimento sob a forma de vegetais. A moradia, vestimentas e a alimentação assumiram novos formatos ao longo da história, no entanto, os recursos naturais para que estas relações aconteçam não permanecem os mesmos.

É sabido, na ciência geográfica, que os recursos naturais estão dispersos de forma diferenciada no território. Com o geógrafo Ratzel este fenômeno foi perceptível ao considerar a importância do território e dos recursos ali contidos para a perpetuação da vida humana. Neste contexto, possuir territórios era sinônimo de possuir os recursos naturais (COSTA, 1998 e RIBEIRO, 2001).

$\mathrm{O}$ acesso aos recursos para que a humanidade garanta sua existência assume na atualidade dimensões que transcendem as escalas dos territórios pertencentes aos Estados Nacionais. Este novo ritmo de acesso inaugurado com a sociedade industrial, impôs uma nova lógica de acesso aos recursos naturais. A sociedade capitalista industrial, deste modo, alicerçou-se produzindo um ritmo muito mais acelerado de acesso e utilização dos recursos naturais se comparado às sociedades pré-capitalistas.

Esta nova lógica para acesso aos recursos naturais pode ganhar fôlego quando relacionada com cenário amazônico. Este em Becker (2005) é considerado uma nova fronteira de capital natural e, porventura mercantilizada de múltiplas maneiras. Esta mercantilização pode ocorrer na direção do impedimento do desmatamento perante a percepção de que a floresta deve ser preservada para a manutenção da ecologia nela contida - ou - o desmatamento, onde o que prevalece são os interesses da pecuária, soja e madeireiras.

Como consequência deste cenário anterior tem-se a inquietação da sociedade mundial diante das perguntas: perpetuar o acesso aos recursos naturais e intensificar o aumento da crise ambiental? Existem soluções dentro do sistema capitalista para eliminar o impasse entre acesso aos recursos naturais e aumento da crise ambiental? Como garantir recursos naturais suficientes para que o modelo de civilização atual continue a existir? Em Ribeiro tem-se uma direção para esta questão:

\section{A produção de objetos na dimensão capitalista predominante também torna o ambiente um fator central para a reprodução do capital. Um modo de produção baseado na produção contínua de objetos, que os torna passiveis de ser descartados mesmo que em total condição de uso, necessita repor a base material usada para fabricá-los. E de muita energia para alterar as condições naturais dos recursos naturais (RIBEIRO, 2010, p.2).}

O falido modelo econômico, que insiste em se disfarçar de verde, pretende submeter todos os ciclos vitais da natureza às regras do mercado e ao domínio da tecnologia, da privatização e da mercantilização da natureza e suas funções, aumentando os mercados financeiros especulativos através dos mercados de carbono, de serviços ambientais, de compensações por biodiversidade e o mecanismo redução de emissões por diminuição das porcentagens de desmatamento. Todas estas ações são criadas para evitar a produção excessiva das externalidades negativas (MARTÍNEZ-ALIER, 2007).

O modo de produção vigente, inegavelmente, produz as externalidades negativas e, também cria um campo de protesto por parte dos movimentos socioambientais vítimas desta lógica. Sendo assim, surge o campo de luta contra a ordem estabelecida buscando legitimar uma justiça ambiental.

Acselrad (2010) alertou para a mobilização dos atores diante de injustiças ambientais como resultado da lógica perversa de um sistema de produção, de ocupação do solo, de destruição de ecossistemas, de alocação espacial de processos poluentes, que penalizam as condições de saúde da população trabalhadora, que mora em bairros pobres e é excluída dos grandes projetos de desenvolvimento. 
Essa é uma lógica que mantém grande parte da população às margens das cidades e da cidadania, sem água potável, coleta adequada de lixo e tratamento de esgoto. Uma lógica que permite que grupos específicos lucrem com a imposição de riscos ambientais e sanitários aos grupos que, embora majoritários, por serem pobres, têm menos força para serem na sociedade, e, sobretudo, nas esferas do poder.

Essas mobilizações dos atores diante de injustiças ambientais devem-se tanto às dinâmicas sociais e econômicas que dizem respeito aos recursos naturais, quanto à ausência de políticas estatais efetivas que objetivam a implementação de esquemas de gestão disponíveis para a regulação do uso e acesso dos recursos naturais.

Da mesma forma, o avanço das ações de desenvolvimento vai colocando desafios à gestão dos recursos naturais na medida em que exerce pressão para seu uso, o que também pode gerar diferentes tipos de conflitos.

Assim, os conflitos socioambientais se tornaram cada vez mais frequentes nos países da América Latina, onde o atual processo de globalização é, ao mesmo tempo, gerador de desigualdades sociais e de "identidades de resistência", constituídas por atores coletivos que precisam construir formas de resistência e sobrevivência, lutando por justiça social e cidadania num modelo que fortalece assimetrias (CASTELLS, 2010).

Os objetivos principais a serem alcançados seriam o acesso e uso desses recursos naturais ou a necessidade de reconhecimento ou participação no processo de tomada de decisão sobre os mesmos.

A compreensão da atuação da Confederación de Pueblos Indígenas de Bolivia - CIDOB, perante aos impactos socioambientais nas populações indígenas da Amazônia boliviana, pretende fornecer elementos para a análise da formação e da atuação de movimentos sociais frente à questão ambiental e sua influência sobre práticas sociais relacionadas à conservação e sustentabilidade no uso de recursos naturais.

Por meio de suas estratégias, observa-se a ação de contraponto para a lógica de acesso aos recursos naturais bem como sua voz de protesto diante das injustiças ambientais identificadas por Acselrad. ACIDOB, por meio da racionalidade ambiental, segundo Enrique Leff (2001), se legitima enquanto defensora da justiça ambiental.
Dessa maneira, à luz dos conceitos de desenvolvimento sustentável e de racionalidade ambiental, procurou-se verificar como a CIDOB pode contribuir, enquanto um movimento social, para criar uma governança ambiental entendida como um conjunto de instituições que rege o uso dos recursos naturais. Para tanto, utilizou-se como metodologia de trabalho análise de bibliografia sobre o tema e documentos produzidos pela CIDOB, muitos deles acessados eletronicamente.

\section{DESENVOLVIMENTO SUSTENTÁVEL E RA- CIONALIDADE AMBIENTAL}

A discussão para a formulação do conceito de desenvolvimento sustentável iniciou-se em 1987 com a publicação do que foi considerado marco histórico para o ambientalismo mundial e denominado "O Nosso Futuro Comum", mais conhecido como "Relatório Brundtland".

Elaborado pela Comissão Mundial sobre o Meio Ambiente e o Desenvolvimento - criada pelas Nações Unidas e presidida por Gro Brundtland, primeira-ministra da Noruega na época, tal texto critica as nações desenvolvidas e industrializadas do período que exportam pobreza e poluição para o planeta. Porém, também ressalta a necessária busca de eficiência econômica, com justiça social e harmonia ecológica.

Este relatório deixou bem clara sua proposta: a exploração dos recursos naturais, os investimentos econômicos e o desenvolvimento tecnológico não devem comprometer a construção de um futuro justo, seguro e próspero, embasado na responsabilidade comum com o ambiente do planeta. Sendo assim, o relatório define que "desenvolvimento sustentável é aquele que atende às necessidades do presente sem comprometer a possibilidade das gerações futuras de atenderem as suas próprias necessidades" (GRO BRUNDTLAND 1991, p.46).

Em Sachs tem-se outra definição de desenvolvimento sustentável. Segundo ele, durante as três décadas que separam os eventos "Conferência de Estocolmo", a construção do "Relatório de Brundtland", e a "Cúpula de Johanesburgo" este conceito reformulado agregou avanços epistemo- 
lógicos sobre o mesmo. Portanto, "o desenvolvimento sustentável obedece ao duplo imperativo ético da solidariedade com as gerações presentes e futuras, e exige a explicitação de critérios de sustentabilidades social e ambiental e de viabilidade econômica" (SACHS, 2009, p.36).

Todavia, a construção de Veiga para o desenvolvimento sustentável e seu alerta de que este conceito ainda não foi totalmente dissecado é a via estabelecida para análises neste artigo, pois,

(...) em meio a tantas linhas especulativas, o que parece se destacar é uma forte visão convergente de que as sociedades industriais estão entrando em uma nova fase de sua evolução. E que essa transição será tão significativa quanto aquela que tirou as sociedades europeias da ordem social agrária e levou-as à ordem social industrial. Ao mesmo tempo, as diversas versões sobre o desenvolvimento sustentável parecem estar muito longe de delinear, de fato, o surgimento dessa nova utopia de entrada no terceiro milênio. Este é um enigma que continua à espera de um Édipo que o desvende (VEIGA 2005, p.208).

Porventura, o desenvolvimento sustentável objetivado para os povos indígenas, e para as ações da CIDOB, é aquele onde a qualidade de vida está vinculada a diversas formas de identidade e de cooperação, solidariedade, participação e de realização, "que entrelaçam a satisfação de necessidades e aspirações derivadas do consumo com diferentes formas de realização, através de processos de trabalho, de funções criativas e de atividades recreativas" (LEFF 2001, p. 324).

Além disso, o conceito de racionalidade ambiental de Enrique Leff (2001) se apresenta como um novo paradigma de um desenvolvimento alternativo e visto aqui neste trabalho como a possibilidade de afirmativa para o conceito de desenvolvimento sustentável associado ao movimento indígena boliviano.

Segundo LEFF (2001), os movimentos ambientalistas em países pobres se apresentam como uma resposta à destruição da natureza, de suas formas de vida e de seus meios de produção, pois são desen- cadeados por conflitos sobre o acesso e o controle dos recursos e pela reapropriação social da natureza relacionado à defesa dos seus territórios, de suas identidades étnicas, autonomia política e manutenção de seus estilos de desenvolvimento.

A racionalidade ambiental, segundo o autor, não é a expressão de uma lógica, mas o efeito de um conjunto de interesses e de práticas sociais que articulam ordens materiais diversas que dão sentido e organizam processos sociais através de certas regras, meios e fins socialmente construídos. Desta forma, a categoria racionalidade ambiental se apresenta como social (LEFF, 2007).

A racionalidade ambiental também permite a análise do impacto do discurso ambientalista (objetivos, valores e práticas) no discurso político e nas políticas econômicas, na ressignificação das demandas e reivindicações dos grupos sociais, além do desvendamento das estratégias de poder destes movimentos da sociedade civil para transformar a racionalidade dominante.

Desta maneira, a racionalidade ambiental enquanto categoria de análise possibilitaria incorporar os valores éticos e princípios produtivos do ambientalismo, além da observação da internalização dos princípios do ambientalismo nos direitos culturais emergentes e na perspectiva de um desenvolvimento nacional multiétnico (LEFF 2001, p.107-108). As identidades coletivas locais passam assim a constituir um dos discursos nos quais se expressam esses conflitos (MARTÍNEZ-ALIER 2007, p.344).

E, apesar de cada grupo social ter uma forma de relação e apropriação dos recursos naturais, movimentos sociais ou indígenas podem melhorar suas demandas imediatas por meio da incorporação de uma consciência ambiental, que incide, por exemplo, nos padrões de uso de seus recursos (LEFF, 2007). Sendo assim, o conceito de desenvolvimento sustentável e racionalidade ambiental se inserem como conceitos de fortalecimento da legitimidade das identidades coletivas. A organização não governamental CIDOB se inclui nesta conjectura. 


\section{A CIDOB E O MOVIMENTO INDÍGENA DO ORIENTE BOLIVIANO}

Uma história marcada por insurreições, guerrilhas e greves gerais fez com que a Bolívia fosse considerada por muitos como um dos países mais instáveis da América. Desde a década de 1970, em decorrência da conjuntura política da época, os movimentos sociais na Bolívia exercem influência política direta ou indireta no país.

A Bolívia, que possui uma população majoritariamente indígena sempre presente em seu cenário político-histórico, pode vivenciar até os anos 90 uma expressiva presença do movimento operário mineiro (ARANDA, 2004), devido à aplicação de políticas neoliberais à sua economia e à reestruturação das relações sociais no âmbito global.

Mas, a partir da década de 1990, se observa de maneira mais incisiva, a ascensão de movimentos sociais baseados em "novas identidades", como a indígena. Os movimentos indígenas começaram a se tornar protagonistas políticos importantes na Bolívia, "diferenciando-se dos movimentos tradicionais, singularizados pela divisão de classes" (LEMGRUBER 2006, p.3).

Foi durante esse período que se estabeleceram diversas organizações como a CIDOB. A CIDOB, uma Organização Não Governamental (ONG) fundada em 1982 em Santa Cruz de la Sierra, é a representante nacional do movimento indígena na Bolívia.

A denominação em inglês No Governamental Organizations (NGOs), usada pela primeira vez nas Nações Unidas, em 1950, refere-se às organizações que atuam em nível supra e internacional, e que não foram estabelecidas por acordos governamentais. Em 1996, as Nações Unidas ampliou esta definição de NGOs denotando ainda a particularidade de serem organizações não governamentais que atuam em nível supra e internacional, mas, também na escala local e nacional.

Estas organizações não governamentais são formadas por qualquer grupo de cidadãos voluntários com interesses comuns sem visão de fins lucrativos e com o propósito de realizar serviços humanitários, supervisionar política no nível da comunidade. Servem também para ajudar a implementar acordos internacionais e se organizam em responder a problemas que envolvam meio ambiente, direitos humanos e a saúde (ZIGLIO 2012, p.50).
A CIDOB foi a "primeira organização interétnica, constituída (...) para coordenar e organizar os grupos étnicos das terras baixas" (ARANDA 2004, p. 92). Na ocasião da sua fundação, houve a participação de representantes dos seguintes povos indígenas do Oriente boliviano: Guaraní-izoceños, Chiquitanos, Ayoreos e Guarayos.

Posteriormente em 1998, a CIDOB já contava com a participação de 34 povos indígenas, habitantes de todos os Departamentos da Bolívia, reunidos em organizações regionais, que mediante sua luta constante, conseguiram o reconhecimento de comunidades indígena como sujeitos jurídicos. Além disso, essas populações vêm, ao longo da História, tentando se integrar à vida política do país, às suas leis e processos de solução de conflitos.

A CIDOB começou a ganhar visibilidade em nível nacional com a "Marcha pelo Território e a Dignidade", em 1990. A marcha tinha como principal meta pressionar o Estado, a fim de que esse promulgasse o direito à terra de vários povos indígenas do departamento amazônico do Beni (COSTA, 2011, p. 51).

A CIDOB é reconhecidamente como movimento popular que estabelece relações institucionais com diversas instâncias do Estado " $a$ nivel nacional, con gobiernos locales con organizaciones populares nacionales e internacionales, con organizaciones públicas o privadas del desarrollo y cooperación" (CIDOB, 2010).

Atualmente, em todos os partidos políticos da Bolívia existem representantes de povos indígenas, embora o caráter multiétnico do Estado e dos direitos das populações indígenas ainda não seja aceito na totalidade pela sociedade boliviana (JIMÉNEZ, 2010).

O objetivo principal da CIDOB é assegurar os títulos de terras para o território indígena, pois, apesar do Estado ter estabelecido a base legal para que esse fato ocorra, sua realização na prática se torna muito difícil devido à oposição dos setores latifundiários da sociedades.

Para que esse processo se concretize, um dos projetos da CIDOB consiste na criação de uma rede de informações atualizadas sobre as Terras Comunitárias de Origem (TCOs) e os conflitos e negociações decorrentes do processo de titulações e aproveitamento de recursos naturais. 
Assim, os povos indígenas das terras altas ou baixas da Bolívia, ao participar no ordenamento e titulação de suas Terras Comunitárias de Origem (TCOs) estarão contribuindo, portanto, para o diálogo, resolução de conflitos e promoção dos direitos indígenas em âmbito nacional, além da promoção do desenvolvimento sustentável que contemple a identidade cultural desses povos.

Um dos seus principais projetos é o Centro de Planejamento e Gestão Territorial Indígena (CPTI), que tem como objetivo o aumento da participação da população indígena no desenvolvimento econômico e político da Bolívia, atuando em instituições públicas nos âmbitos nacional e local, a fim de promover os direitos indígenas, identidade cultural e um desenvolvimento sustentável para os povos indígenas (CIDOB 2010, p. 1).

A CIDOB mantém ainda Centros de Computação (CC) e de Documentação (CENDIC) apoiados por equipes técnicas. A Confederação afirma que, através da manutenção de uma Base de Dados atualizada, as organizações terão ao seu alcance, através da Rede Mundial de Computadores, informações importantes sobre como os atores do processo, nos âmbitos nacional e internacional, de maneira que se possa dar continuidade e exercer pressão social sobre as instâncias correspondentes em apoio às demandas indígenas (CIDOB, 2011).

Outras áreas de atuação importantes da Confederação são a proteção aos recursos genéticos e a conservação dos conhecimentos tradicionais indígenas, já que a crescente pressão de indústrias farmacêuticas, que buscam novos recursos biológicos em zonas indígenas tem sido a principal causa da bioprospecção e biopirataria no país.

Dessa maneira, tornou-se necessária a criação de regulamentações para o acesso aos recursos genéticos, em cuja formulação participou ativamente a CIDOB, a fim de garantir a participação dos grupos indígenas na repartição de benefícios. Porém, deve-se ressaltar que, apesar da grande participação dos indígenas no processo democrático formal, observa-se que esse fato não tem sido condição suficiente para a igualdade de direitos.

\section{Obras de infraestrutura em territórios indígenas}

O processo de globalização, expresso em projetos como a IIRSA-Iniciativa para a Integração da Infraestrutura Regional Sul-Americana, ou no projeto de construção de uma nova rodovia no Território Indigena e Parque Nacional Isiboro Sécure -TIPNIS, coloca as populações indígenas e seu patrimônio (extensos territórios, biodiversidade, depósito de minerais e conhecimentos tradicionais) em destaque no conflito de interesses que envolve uma grande parcela da população local e mundial.

O principal empreendimento da IIRSA é o Complexo Hidrelétrico do Rio Madeira (IIRSA 2009). A IIRSA pretende, através de dez eixos de integração, chamados EIDs, traçar novas rotas adequada à geografia econômica do século atual. Desta forma, a região Amazônica torna-se o centro do continente, mesmo não sendo a parte do continente onde passam os fluxos mais densos, localizados ao Sul (THERY, 2005).

O Eixo do Brasil-Peru-Bolívia é considerado um dos principais da IIRSA não só devido ao seu caráter estratégico, mas também devido às potencialidades e riquezas naturais da região, considerando a Amazônia uma região de importância primordial no desenvolvimento dos processos de integração física, das comunicações e da energia, que permitirão aproximar os mercados intra-amazônicos, tratando-se de uma nova escala para pensar e agir na região (IIRSA 2009; Cecenã e Motto 2007; Becker 2005).

Este Eixo é composto por três grupos de projetos, sendo o principal deles aquele que engloba o Complexo Hidrelétrico do Rio Madeira, o maior projeto hidroenergético da Região Amazônica, pois ele engloba o Rio Madeira, segundo rio mais caudaloso depois do Rio Amazonas.

O projeto é composto de quatro hidrelétricas, sendo duas delas localizadas em Rondônia, no Brasil, próximas à fronteira com a Bolívia: são elas as usinas de Santo Antônio e Jirau, em fase de construção, que somariam juntas cerca de 6450 MW de potência instalada (IIRSA, 2009). 
A outra represa se localiza em território boliviano, Cachuela Esperanza, e se encontra em fase avançada de estudo. A represa de Guajará-Mirim, localizada em águas binacionais Brasil- Bolívia, se encontra em fase de estudos iniciais (IIRSA, 2009). Porém, o projeto em si considera apenas as hidrelétricas de Santo Antônio, com localização a $5 \mathrm{~km}$ rio acima do centro de Porto Velho, a capital de Rondônia (Brasil), com mais de 270 mil habitantes na área urbana, e a de Jirau, $136 \mathrm{~km}$ rio acima; juntas, com previsão de inundação de uma área de $529 \mathrm{~km}$ (IIRSA, 2009, AMIGOS DA TERRA-ECOA, 2007).

As construções das represas do Rio Madeira vêm somar-se ao processo de destruição que há décadas está em andamento na Amazônia, embora atualmente exista "uma nova consciência quanto aos riscos das represas" (MARTÍNEZ ALIER 2007, p. 181). E como o fluxo de água e a maior parte dos impactos não obedecem às fronteiras internacionais, existe o risco de que esses impactos afetem o Peru e a Bolívia (FOBOMADE, 2010).

As áreas protegidas nos limites das áreas de influência direta e indireta das represas, tanto Terras Indígenas, como Unidades de Conservação e suas áreas limítrofes, apesar de sua denominação, apresentam um alto grau de vulnerabilidade, principalmente em relação ao aumento da atividade madeireira e ao avanço do desmatamento (PAZ, 2006).

Assim, verificam-se áreas frágeis que acumulam passivos, conflitos de convivência entre a população local, população indígena e os migrantes; rupturas de comunidades locais e indígenas; surgimento de novas localidades sem a adequada infraestrutura; aumento da prostituição e da violência, enfermidades, entre outras consequências.

Desta forma, as hidrelétricas do Rio Madeira, obras integrantes do projeto IIRSA na Região constituem-se em um novo elemento estrutural, gerador de novos arranjos, evidenciando o político e o poder de uso no território, "resultando em conflitos entre os agentes atuantes e mudanças no ordenamento territorial, dando-lhes características vinculadas a multidimensionalidade das escalas geográficas de objetivação social" (CAVALCANTE 2008, p.9).
Em 2008, foi realizado um Encontro na cidade de Santa Cruz de la Sierra, intitulado "IIRSA: ENERGÍA, TRANSPORTE Y PUEBLOS INDÍGENAS". Esse Encontro, patrocinado pela CIDOB, dentre outras ONGs, teve como finalidade discutir os impactos produzidos principalmente pelas obras do Complexo do Rio Madeira na Amazônia boliviana, principalmente nas terras indígenas da Região.

$\mathrm{Na}$ Ata do Encontro, ficou registrado o descontentamento das comunidades indígenas afetadas pelas obras do Complexo e o receio da fragmentação dos territórios indígenas e a falta de comunicação dos mesmos com as respectivas capitais dos Departamentos envolvidos:

Exigimos al Presidente de la República que por medio de sus Ministros se pueda determinar un nuevo diseño del Proyecto del Corredor Norte con características de transporte nacional, evite el excesivo endeudamiento nacional, el cambio de trazo para evitar la fragmentación de los territorios indígenas y que permita la conexión de las comunidades con las capitales de departamentos (...) Crear una instancia nacional del Estado que institucionalice la participación directa y activa de los pueblos indigenas y otros sectores sociales en las decisiones de la Gestión Socioambiental de Carreteras (CIDOB 2008, p.1).

Outro compromisso assumido pela CIDOB na ocasião foi a necessidade da capacitação técnica de seus membros referente à IIRSA (CIDOB, 2008). Esta preocupação ocorreu devido à percepção de que os impactos socioambientais gerados pela IIRSA afetam invariavelmente as populações mais vulneráveis, no caso as populações indígenas, que não têm a oportunidade de reivindicar reparação de danos sem enfrentar processos desequilibrados de negociações.

Em novembro de 2010, os 34 povos indígenas do Oriente, Chaco e da Amazônia boliviana, componentes da CIDOB, realizaram a XV Grande Assembleia Nacional dos Povos Indígenas na cidade de Santa Cruz, na Bolívia. Nessa ocasião, emitiram uma Resolução onde reafirmaram e condenaram os procedimentos das instâncias encarregadas de 
levar adiante o processo de Consulta Prévia Livre e Informada sobre o projeto hidrelétrico de Cachuela Esperanza, já que esse projeto não havia sido ainda apreciado pelo movimento indígena (CIDOB, 2010).

Outro caso exemplar da atuação e engajamento da CIDOB nas questões socioambientais do país refere-se ao projeto de construção de uma estrada que atravessaria um vasto território indígena e Parque Nacional conhecido por TIPNIS.

Essa região, que desde 1990 se chama oficialmente Território Indígena Parque Nacional Isiboro Sécure -TIPNIS, ganhou em 2011 as manchetes da imprensa internacional pela luta de seus habitantes contra a estrada promovida pelo presidente da Bolívia Evo Morales e financiada pelo Brasil, e que deverá atravessar essa reserva ecológica ao meio.

O TIPNIS abrange 1,2 milhões de hectares do centro da Bolívia, entre os departamentos de Cochabamba e Beni, onde vivem 14 mil índios das etnias trinitaria-moxeña, yuracaré e chimán, no meio de um extraordinário habitat animal e vegetal.

Relatórios oficiais identificaram no TIPNIS 714 espécies de fauna e três mil de flora. Outros estudos detalham 108 espécies de mamíferos, 470 de aves, 39 de répteis, 53 de anfíbios e 188 de peixes e mamíferos nadadores como o boto cor-de-rosa, em risco de extinção, segundo dados citados pela Fundação Terra. A biodiversidade é favorecida por 170 lagoas e as diversas altitudes do parque, entre os 180 metros em que estão os rios Isiboro e Sécure e os três mil das serras subandinas.

O território adquiriu o status de Parque Nacional e Território Indígena após uma primeira passeata de nativos que subiram da Amazônia até La Paz em 1990, para se queixar das primeiras invasões de camponeses, criadores de gado e madeireiros.

Essa estrada é uma ramificação do projeto da IIRSA, que contribui para aprofundar as velhas práticas extrativistas da Bolívia, subordinando o país aos projetos discutíveis de integração ao mercado mundial. Dessa forma, a construção dessa nova estrada propiciaria a oportunidade para que o capitalismo global efetuasse um novo movimento de uma "nova territorialidade", desconsiderando-se as relações tradicionais e ancestrais da comunidade com a terra.
Segundo Haesbaert, atualmente "o território pode ser visto nas mais diversas escalas e através de uma concepção muito mais ampla de poder (...), que inclui até mesmo a apropriação simbólica de espaços que, desta forma, para os grupos que se identificam com eles, leva a uma espécie de empoderamento" (HAESBAERT 2011, p.3).

Os diversos grupos indígenas do Oriente, representados pela CIDOB, exigem o direito de se "territorializar" novamente, pois existe o perigo iminente da nova territorialização por aqueles que buscam unicamente explorar a terra como um espaço útil, desprovido de todo o simbolismo mítico e sagrado. Esta é um das principais causas do conflito lá existente.

Além disso, os colonos do TIPNIS temem o avanço do cultivo da folha de coca neste território, enquanto muitos grupos indígenas reivindicam que muitas áreas da Região possam integrar o processo de reforma agrária. Esses grupos temem que a nova estrada provoque desmatamento e facilite a entrada de madeireiros ilegais, acabando com a enorme biodiversidade e ameaçando a cultura e as tradições locais.

A Constituição Política da Bolívia reconhece que os habitantes do lugar decidam quando em suas terras sejam executadas obras ou explorados os recursos naturais. Contudo, indígenas contrários à estrada no TIPNIS afirmam que a recém-aprovada Lei 222 viola a essência e o conceito de "consulta prévia".

Com a marcha e a pressão da CIDOB e de vários setores da Bolívia e de outros países, o então presidente boliviano Evo Morales sancionou a Lei 180, de outubro de 2011 (GACETA OFICIAL DEL ESTADO PLURINACIONAL DE BOLIVIA, 2013), que proibia a construção de qualquer estrada no parque e declarava o território como zona intangível.

Depois de quatro meses, Morales promulgou a Lei 222, de fevereiro de 2012 (GACETA OFICIAL DEL ESTADO PLURINACIONAL DE BOLIVIA, 2013), de Consulta Prévia, para continuar a construção da estrada através do parque. Assim, esse impasse ainda continua e sem um desfecho satisfatório. 
Cabe destacar que não tem sido considerado o procedimento de consulta aos povos indígenas afetados pelos megaprojetos, em conformidade com as normas internacionais como a Convenção 169 sobre Povos Indígenas e Tribais da Organização Internacional do Trabalho da OIT (Organização Internacional do Traba1ho) das Nações Unidas (1989), ratificada pela Bolívia.

Percebe-se então, que a desconstrução da racionalidade capitalista passa a requerer a construção de outra racionalidade social, realizada por novos atores, que vêm se destacando no cenário político, pois "dos conflitos que nascem da racionalidade social dominante emergem movimentos sociais caracterizados por suas novas demandas, formas de organização e estratégias de luta" (LEFF 2001, p. 104), trazendo novos horizontes para as formas de luta pelo poder.

Desta maneira, os movimentos sociais, como os realizados pelas populações indígenas da Amazônia boliviana, via CIDOB, que surgem mobilizados por um conceito de racionalidade ambiental, poderão encontrar a orientação de suas ações e de suas estratégias políticas, fortalecendo assim seu papel de protagonistas políticos para a sociedade civil organizada da Bolívia.

\section{REFLEXÕES FINAIS}

Grande parte do território da Região Amazônica está sendo transformado em valor de troca, através de diversos processos de espoliação, expressos tanto na ocupação e incorporação de terras quanto no represamento de rios visando a produção de energia.

Como então, distribuir de forma equitativa os custos e benefícios implícitos no projeto do Complexo Rio Madeira ou na estrada do TIPNIS, entre os diversos atores envolvidos nesse processo? Essa questão, para ser resolvida precisaria, dentre outros fatores, readequar os modelos de gestão dos empreendimentos e reconhecer a discrepância de poder existente entre os diversos atores envolvidos.

$\mathrm{O}$ acesso à informação, o reconhecimento dos movimentos sociais ou outras formas de representação popular e a capacitação de agentes voltada à negociação de processos legais são outras ações importantes para a superação dos desafios aqui apontados.
Fiscalizar o cumprimento da legislação vigente por parte do Estado e dos agentes econômicos; promover alternativas sustentáveis para a utilização dos recursos naturais e, finalmente, apoiar o fortalecimento de movimentos sociais e organizações como a CIDOB, para o acesso e a gestão dos recursos naturais, são ações necessárias para a conquista de direitos de cidadania.

Movimentos sociais como a CIDOB poderiam tomar a iniciativa de criar mecanismos de gestão dos recursos naturais que incluam transformações produtivas mais justas e igualitárias.

Essas ações devem contar com a contribuição dos centros de pesquisa e tecnologia; do movimento ambientalista e de redes temáticas, visando a capacitação técnica dos atores envolvidos; a promoção do intercâmbio de informações; a difusão de experiências e a coordenação de ações para a proteção socioambiental.

\section{REFERÊNCIAS}

ACSELRAD, Henri. Ambientalização das lutas sociais: o caso do movimento por justiça ambiental. In: Revista Estudos Avançados. [online] São Paulo: Universidade de São Paulo, 2010,vol.24,nº68. Disponível em:

$<$ http://www.scielo.br/scielo.php?script=sci_arttext\& pid $=S 010340142010000100010 \& \operatorname{lng}=$ pt\&nrm=iso $>$. Acesso em: 12 jan. 2013.

AMIGOS DA TERRA-ECOA. O maior tributário do Amazonas ameaçado. S.1.: agosto de 2007. 22 p.

ARANDA, Andrés. A questão indígena no cenário político boliviano. In: REUNIÃO DE ESTUDOS: ASCENSÃO DE MOVIMENTOS INDIGENISTAS NAAMÉRICA DO SUL E POSSÍVEIS REFLEXOS PARA O BRASIL (BRASÍLIA, 2004). I Reunião de Estudos: Ascensão de Movimentos Indigenistas na América do Sul e possíveis reflexos para o Brasil. Brasília: Gabinete de Segurança Institucional; Secretaria de Acompanhamento e Estudos Institucionais, 2004. 117 p. 
ASAMBLEA LEGISLATIVA PLURINACIONAL. Ley 180 de protección del Territorio Indígena y Parque Nacional Isiboro Sécure- TIPNIS. Bolivia: Gaceta Oficial del Estado Plurinacional de Bolivia, 24 de octubre de 2011. Disponível em $<\mathrm{http}$ ://www. gacetaoficialdebolivia.gob.bo/normas/buscar/180>. Acesso em 08 jan. 2013.

\section{ASAMBLEA LEGISLATIVA PLURINACIONAL.} Ley 222 de consulta a los pueblos indígenas del Território Indígena y Parque Nacional Isiboro Sécure- TIPNIS. Bolivia: Gaceta Oficial del Estado Plurinacional de Bolivia, 10 de febrero de 2012. Disponível em $<$ http://www.gacetaoficialdebolivia.gob.bo/normas/ buscar/222>. Acesso em 08 jan. 2013.

BANK INFORMATION CENTER-BIC. Complejo hidroeléctrico del río Madeira. 2009.

3 p. Disponível em: $<$ http://www.bicusa.org/es/Project.10138.aspx>. Acesso em: 20 de março de 2012.

BECKER, Bertha K. Geopolítica da Amazônia. Estud. Av., São Paulo, v. 19, n. 53, 2005. Disponível em: <http://dx.doi.org/10.1590/S0103$40142005000100005>$. Acesso em 13 Jan. 2013.

CASTELLS, Manuel. O poder da identidade (A era da informação: economia, sociedade e cultura; vol. 2). São Paulo: Paz e Terra, 2010. 344 p.

CAVAlCANTE, Maria Madalena de A. et all. Políticas Territoriais e Mobilidade Populacional na Amazônia: Estudo sobre as Hidrelétricas de Jirau e Santo Antônio no Rio Madeira/ Rondônia/Brasil. In: XVI ENCONTRO NACIONAL DE ESTUDOS POPULACIONAIS. Anais... Caxambú: ABEP, 2008. pp. 3-18.

CECEÑA, Ana Esther, AGUILAR, Paula, MOTTO, Carlos. Territorialidad de la dominación. Integración de la Infraestructura Regional Sudamericana (IIRSA). Buenos Aires: Observatorio Latinoamericano de Geopolítica, 2007. 60 p.
CHAV, Maria do Perpetuo Socorro et all. Conflitos socioambientais e identidades políticas na Amazônia. Achegas.net, Rio de Janeiro: 2008, n. 37, p. 42-57, 2008. Disponível em $<\mathrm{http} / / / w w w . a c h e g a s . n e t / n u m e-$ ro/37/maria_37.pdf $>$. Acesso em 13 jan. 2013.

CIDOB. Acta de Taller IIRSA: energía, transporte y pueblos indígenas. Santa Cruz de la Sierra, 03 jul. 2008. Disponível em: <http://www.cidob-bo.org/>. Acesso em 13 jan. 2013.

CIDOB. Confederación de Pueblos Indígenas de Bolivia. 2011. Disponível em: <http://www.cidob-bo. org/>. Acesso em: 12 jan. 2013.

CIDOB. Resolucion de la XV Gran Asamblea $\mathrm{Na}$ cional de Los Pueblos Indígenas. Los 34 Pueblos Indígenas del Oriente, Chaco y Amazonia a través de sus 12 Regionales. Santa Cruz: 25 nov. 2010. 3 p. Disponível em: < http://www.cidob-bo.org/images/2010/ ganpi2010/19.-\%20RESOLUCION\%20RR.NN\%20 HIDROELECTRICA.pdf > . Acesso em 12 jan. 2013.

COSTA, Vicente. Gestión ambiental y regionalización: una aproximación histórica al caso español. Scripta Nova, Revista Electrónica de Geografía y Ciencias Sociales. Barcelona, vol. VI, nº 16, 1998. Disponível em: <http://www.ub.edu/geocrit/sn-16.htm>. Acesso em 28 de ago. de 2012.

ESCÁRZAGA, Fabiola. La emergencia indígena contra el neoliberalismo. Politica y Cultura, México, n. 22, p. 101-121, 2004.

FOBOMADE. Hidroeléctrica Jirau en el río Madera un desarrollo no sostenible. Disponível em: $<\mathrm{http}$ ://www. fobomade.org.bo/ > . Acesso em 12 de março de 2010. 
HAESBAERT, Rogério. Da multiterritorialidade aos novos muros: paradoxos da desterritorialização contemporânea. Niterói, Universidade Federal Fluminense, 2011. p.1-15. Disponível em $<\mathrm{http}: / / \mathrm{www}$. posgeo.uff.br/sites/default/files/da_multiterritorialidade_aos_novos_muros.pdf $>$. Acesso em 02 jan. 2013. IIRSA. Iniciativa para la Integracion de la Infraestructura Regional Suramericana. Disponível em: $<$ http://www.iirsa.org/>. Acesso em: 08 de jan. de 2013.

JIMÉNEZ, Maryhen. La situacion de los pueblos indígenas de Bolivia. abril de 2010. Alianza del Clima . Disponível em $<$ http://indigene.de/index. php?id=28\&L=2>. Acesso em 12 jan. 2013.

LEFF, Henrique. Saber Ambiental: sustentabilidade, racionalidade, complexidade, poder. Petrópolis: Vozes, $2001.343 \mathrm{p}$.

LEFF, Henrique. Epistemologia Ambiental. São Paulo: Cortez, 2007. 239 p.

LEMGRUBER, Ana Carolina Delgado e Silva. Os movimentos indígenas e suas implicações para o processo político na Bolívia e no Peru. Observador On-line. Vol. 1, no 4, p. 1-16, 2006. Disponível em $<$ http://www.blogdoalon.com/ftp/observador_v1n4. pdf>. Acesso em 06 jan. 2013.

MARTÍNEZ - ALIER, Joan. O ecologismo dos pobres: conflitos ambientais e linguagens de valoração. São Paulo: Contexto, 2007. 383 p.

PAZ, Luciana Leal da. Hidrelétricas e Terras Indigenas na Amazônia: Desenvolvimento Sustentável? Tese (doutorado). Universidade Federal do Rio de Janeiro. Rio de Janeiro: 2006. 243p.
PORTO-GONÇALVES, Carlos Walter. De saberes e de territórios: diversidades e emancipação através da experiência latino: americana. Niterói: UFF Universidade Federal Fluminense, S. d. p. 37-51. Disponível em <http://www.posgeo.uff.br/sites/default/files/ texto_carlos_walter.pdf $>$. Acesso em 02 jan. 2013.

RIBEIRO, Wagner. Teorias socioambientais: em busca de uma nova realidade. Revista Estudos Avançados. São Paulo, vol 24, nº 68, 2010. Disponível em: < http://www.scielo.br/scielo.php?pid=S0103$-40142010000100003 \&$ script $=$ sci_arttext $>$. Acesso em 11 jan. 2013.

RIBEIRO, Wagner. A ordem ambiental internacional. São Paulo: Contexto, 2001. 176p.

THERY, Hervé. Situações da Amazônia no Brasil e no continente. Estudos Avançados, São Paulo, vol. 19, no. 53 p. 37-49. 2005. Disponível em:

$<$ http://revistas.usp.br/eav/article/ view/10045/11617>. Acesso em 12 jan. jul. 2013.

URUGUAY SUSTENTABLE-REDES. IIRSA. Otro paso em la explotación de los pueblos y territórios sudamericanos. Montevideo: Uruguay Sustentable-Redes-AT, 2006.

VEIGA, José Eli da. Desenvolvimento sustentável: o desafio do século XXI. Rio de Janeiro: Garamond, 2005. 226pg

ZIGLIO, Luciana Aparecida Iotti. Redes socioambientais e a cooperação internacional: GARSD. 2012. Tese (Doutorado em Geografia Humana) - Faculdade de Filosofia, Letras e Ciências Humanas, Universidade de São Paulo, São Paulo, 2012. Disponível em: $<$ http://www.teses.usp.br/teses/disponiveis/8/8136/ tde-27092012-113608/>. Acesso em 12 jan. 2013. 